\title{
Spatial Distribution Balance Analysis of Hospitals in Wuhan
}

\author{
Nai Yang ${ }^{1, *}$, Shiyi Chen ${ }^{1}$, Weilu $\mathrm{Hu}^{1}{ }^{1}$, Zhongheng $\mathrm{Wu}^{2}$ and Yi Chao ${ }^{1}$ \\ 1 Faculty of Information Engineering, China University of Geosciences, 388 Lumo Road, Wuhan 430074, \\ China; unichsy@163.com (S.C.); 15172508548@163.com (W.H.); chaoyi@cug.edu.cn (Y.C.) \\ 2 NavInfo Co., Ltd., F16-17, TowerA, Beijing Phoenix Place, A-5, Shuguang Xili, Chaoyang District, \\ Beijing 100028, China; keykeywu@hotmail.com \\ * Correspondence: naigeer@163.com; Tel.: +86-150-7231-2496
}

Academic Editor: Derek Clements-Croome

Received: 11 August 2016; Accepted: 26 September 2016; Published: 30 September 2016

\begin{abstract}
The spatial distribution pattern of hospitals in Wuhan indicates a core in the central urban areas and a sparse distribution in the suburbs, particularly at the center of suburbs. This study aims to improve the gravity and Huff models to analyze healthcare accessibility and resources. Results indicate that healthcare accessibility in central urban areas is better than in the suburbs, where it increasingly worsens for the suburbs. A shortage of healthcare resources is observed in large-scale and high-class hospitals in central urban areas, whereas the resources of some hospitals in the suburbs are redundant. This study proposes the multi-criteria evaluation (MCE) analysis model for the location assessment in constructing new hospitals, which can effectively ameliorate healthcare accessibility in suburban areas. This study presents implications for the planning of urban healthcare facilities.
\end{abstract}

Keywords: hospital; accessibility; spatial distribution; Huff model; multi-criteria evaluation

\section{Introduction}

Numerous countries have created local environments to provide residents access to healthcare resources in response to the initiatives of the World Health Organization [1,2]. However, hospitals vary in type, specialty, scale, and location, and patients often cross town or city boundaries for a doctor or hospital services, which is an inevitable consequence of dispersed populations and medical services [2,3]. Hospital services are strongly consumption- and service-oriented, and they require improved spatial distribution research to maintain socially fair resource allocation, to eliminate spatial polarization, and to reduce spatial differentiation.

Relevant studies have mainly focused on a balanced spatial distribution of medical infrastructure relative to the population, hospital level and scale, and service area. The location quotient is used to measure the degree of spatial aggregation of public service facilities [4] and to evaluate the distribution balance between the public facilities and the population [5]. The balance of medical resource allocation can be indirectly analyzed via the population health distribution determined using the Lorenz curve, the Gini coefficient, and the difference index [6]. A public service facility dominance model based on the gravity model has been developed to describe the healthcare accessibility of an area [7]. Determined using the improved two-step floating catchment area method, this study also reflects the spatial accessibility to primary health care services in different types of rural areas [8,9], and shows in the accessibility scores that there is imbalance in the southwest of Montreal [10]. Accessibility has long been recognized as key to the development of spatial planning strategies [11]. Four categories have been classified as measures of spatial accessibility to healthcare to assess the spatial distribution balance: provider-to-population ratios, distance to nearest provider, average distance to a set of providers and gravitational models of provider influence [12-14]. Patients prefer to choose the best hospitals, and 
the best hospitals always locate in crowed areas. In time, healthcare accessibility varies greatly, which causes spatial heterogeneity for the high-quality hospitals [15]. So the new construction of hospitals should be planned considering population, distance, transportation, and other factors [3,14]. Increased research on medical services and resource allocation for hospital construction is necessary to reduce the costs of medical treatments and to maximize the scope of medical services [16].

This study uses the ArcGIS (Esri, Redlands, CA, USA) to analyze the spatial distribution characteristics of hospitals in Wuhan. This study also utilizes the improved gravity and Huff models to analyze resident healthcare accessibility and medical resource usage, respectively. New medical construction areas in suburbs are assessed for areas lacking medical resources and accessibility based on their distance from existing hospitals and proximity to the population.

\section{Study Area and Data}

Wuhan is the capital of the Hubei Province in the Yangtze River Basin in Central China. The study area was selected using the 2009 Wuhan administrative map from the Hubei Bureau of Surveying, Mapping, and Geoinformation website [17]. The study area includes seven central urban areas (i.e., Jiang'an, Jianghan, Qiaokou, Hanyang, Wuchang, Qingshan, and Hongshan Districts) and six suburban areas (i.e., Dongxihu, Hannan, Caidian, Jiangxia, Huangpi, and Xinzhou Districts. The medical service facilities in this study are based on the Wuhan medical infrastructures. According to different professional fields, the Chinese health care system includes the general hospital, specialized hospital, teaching hospital, and community clinic. A total of 256 hospitals in this paper were divided into general hospitals (providing general or major subject medical service), specialized hospitals (providing a specific disease, special treatment methods and other special medical services), and Chinese traditional medicine hospitals. Furthermore, these hospitals were further categorized as third-, second-, and first-class hospitals on the basis of the quality of medical service and hospital scale. In China, the higher the class is, the better the hospital. A few unrated institutions were assigned to first-class hospitals. The location data were based on the Baidu Map [18]. The number of sickbeds was obtained from official hospital websites. For hospitals without sickbed data, the average sickbed numbers as per the appropriate rank of the hospital were used. For example, the sickbed numbers of a first- and second-class hospitals are 30 and 50, respectively. Land use classification data, as well as the information from 165 population points were obtained from the International Geosphere-Biosphere Program and the Wuhan Statistical Yearbook (2013) [19], respectively. The population points mean the population of the sub-district in accordance to the yearbook, and the location of the point is the location of the sub-district office. The road network data were extracted from ArcGIS Online.

\section{Methods}

\subsection{Spatial Distribution Analysis}

The hospitals in Wuhan are mainly concentrated in the central urban area based on several experiments using point density analysis in ArcGIS within a 2000 scope (Figure 1). This scope of threshold is a parameter of this method which shows a better effect of hospitals aggregation. The densest area is spread along the river, with the hospital concentration, and gradually dispersed to the periphery. Healthcare service is intensive in central suburban areas. However, the supply in the central urban area is higher than in the suburbs (Figure 2). The hospitals are, overall, disproportionally distributed. Most areas do not have hospitals, such as the northern and the southwestern parts of the Hongshan District. 


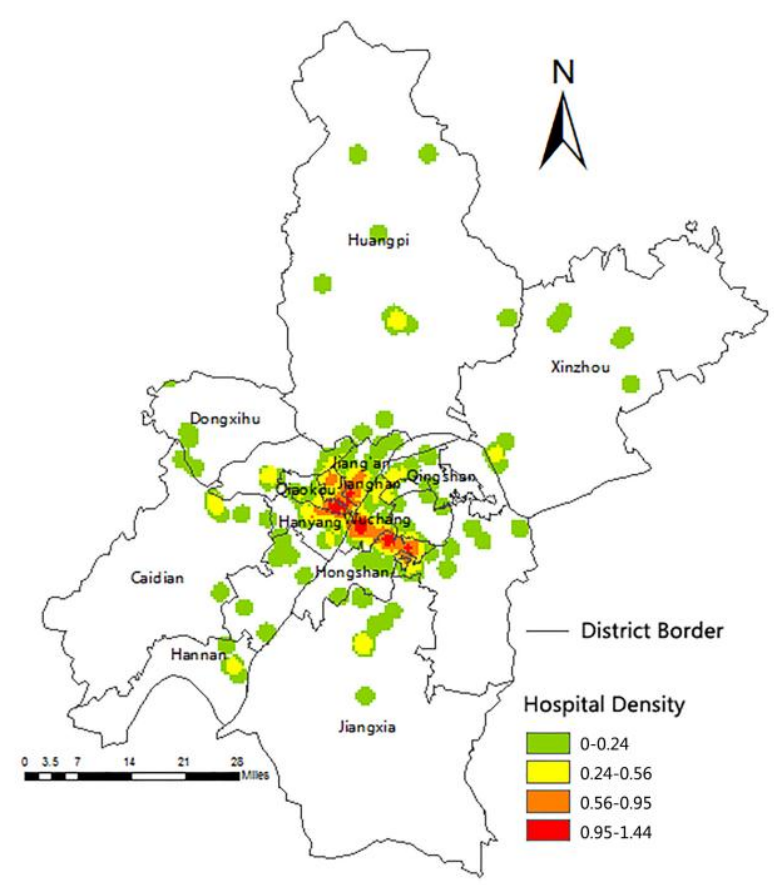

Figure 1. Wuhan hospital density.

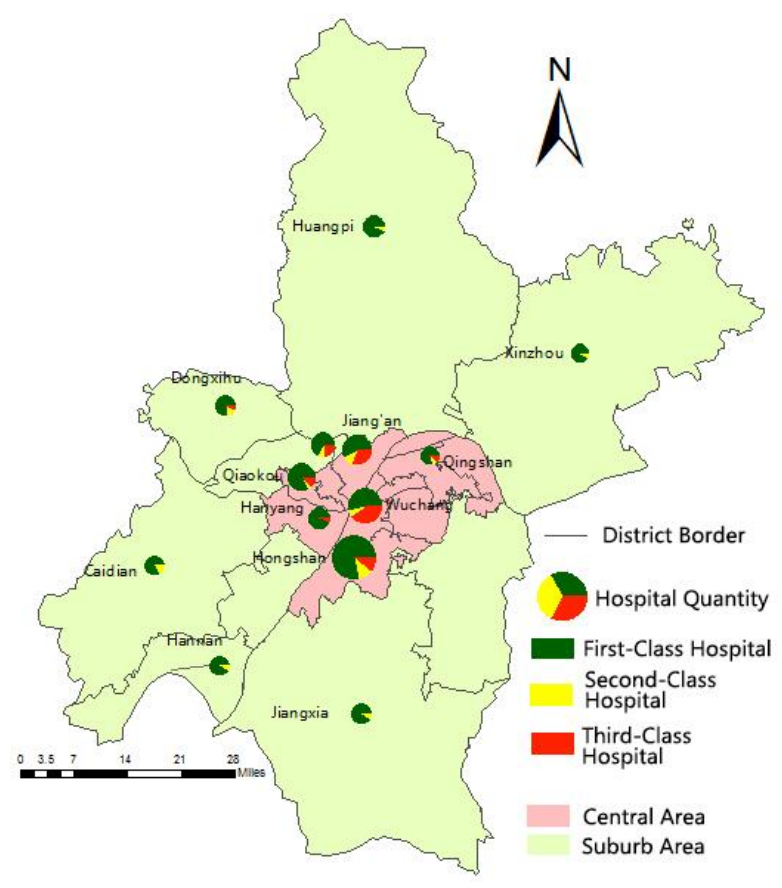

Figure 2. Wuhan hospital distribution.

The spatial distribution density of hospitals in Wuhan is $0.03 / \mathrm{km}^{2}$ (Table 1). The hospital density in the central urban area is $0.23 / \mathrm{km}^{2}$. However, the density in the suburbs is below $0.01 / \mathrm{km}^{2}$. These findings prove that the healthcare coverage rate in the suburbs is lower than that in the central urban area. The core zone of the hospital distribution is located in the Jianghan and Qiaokou Districts. Third-class hospitals are mainly found in the Wuchang District, which accounts for $36.84 \%$ of all third-class hospitals in the Wuhan City (Figure 2). No third-class hospitals are found in the suburbs. 
Table 1. Wuhan hospital information.

\begin{tabular}{|c|c|c|c|c|c|c|c|}
\hline District & Property & $\begin{array}{l}\text { Population } \\
\text { (Thousand) }\end{array}$ & $\begin{array}{c}\text { Acreage } \\
\left(\mathbf{k m}^{2}\right)\end{array}$ & $\begin{array}{c}\text { Population } \\
\text { Density } \\
\text { (person/km²) }\end{array}$ & Hospital & $\begin{array}{c}\text { Hospital } \\
(\%)\end{array}$ & $\begin{array}{l}\text { Density of } \\
\text { the Hospital } \\
\left(\text { place } / \mathrm{km}^{2}\right)\end{array}$ \\
\hline Jianghan & Central & 713.10 & 33.43 & 21,331 & 18 & 7 & 0.538 \\
\hline Qiaokou & Central & 848.30 & 46.39 & 18,286 & 23 & 9 & 0.496 \\
\hline Jiang'an & Central & 926.80 & 64.24 & 14,427 & 26 & 10.2 & 0.405 \\
\hline Wuchang & Central & 1246.80 & 87.42 & 14,262 & 35 & 13.6 & 0.400 \\
\hline Qingshan & Central & 51.26 & 68.40 & 7494 & 10 & 4 & 0.146 \\
\hline Hangyang & Central & 61.67 & 108.34 & 5692 & 14 & 5.5 & 0.129 \\
\hline Hongshan & Central & 147.74 & 480.20 & 3077 & 57 & 22.3 & 0.119 \\
\hline Hannan & Suburb & 12.68 & 287.70 & 441 & 12 & 4.6 & 0.042 \\
\hline Dongxihu & Suburb & 50.06 & 439.19 & 1140 & 13 & 5.1 & 0.030 \\
\hline Caidian & Suburb & 66.34 & 1108.10 & 599 & 11 & 4.3 & 0.009927 \\
\hline Xinzhou & Suburb & 85.57 & 1500.00 & 570 & 10 & 4 & 0.006667 \\
\hline Huangpi & Suburb & 89.78 & 2261.00 & 397 & 15 & 5.8 & 0.006634 \\
\hline Jiangxia & Suburb & 83.40 & 2010.00 & 415 & 12 & 4.6 & 0.005970 \\
\hline Sum & - & 1022.00 & 8494.41 & - & 256 & 100 & 0.030137 \\
\hline
\end{tabular}

The comparison above shows numerous differences among the hospitals in these districts. The hospital quantity is imbalanced between the central urban area and the suburbs. From the perspective of the geographical distribution, the hospitals are widely distributed and have adequate supplies in the central area, whereas the distribution in the suburbs is sparse. Third-class hospitals are all in the central urban area. Moreover, the scale of hospital services is also imbalanced in the central urban area, which includes the Qingshan and Hanyang Districts, which hosts only one third-class hospital.

\subsection{Spatial Accessibility Analysis}

Health service planners require accurate, reliable, and robust measures to determine the spatial variation in the accessibility patterns and to ensure appropriate access to healthcare in the city [20]. Good and equal access to healthcare for the whole population, regardless of geography, remains a key goal of governments and societies [21]. The assessment of the spatial accessibility of medical services for people needs to consider the location, scale, and costs of peripheral hospitals.

\subsubsection{Improved Accessibility Analysis Model}

In 1959, Hansen proposed the first law of geography as a measure of accessibility [22]. He considered all service facilities for the selection, which helped calculate the opportunity-accumulated value easily. $M_{j} / D_{i j}^{\beta}$ is the gravity force from $j$ to $i$, where $M_{j}$ is the scale of $j, D_{i j}$ is the impedance between $i$ and $j$, and $\beta$ is the friction coefficient that describes travel impedance. The gravity model is expressed as following in Equation (1):

$$
A_{i}=\sum_{j=1}^{n} A_{i j}=\sum_{j=1}^{n} M_{j} / D_{i j}^{\beta}
$$

This paper utilized the improved gravity model to calculate the accumulated value of gravitational force to evaluate the degree of healthcare accessibility. The equations are written as following in Equations (2) and (3):

$$
A_{i}=\sum_{j=1}^{n} \alpha_{j} S_{j} / V_{j} D_{i j}^{\beta}
$$

and:

$$
V_{j}=\sum_{i=1}^{m} C_{i} / D_{i j}^{\beta}
$$


where $A_{i}$ is the indicator of healthcare accessibility that represents population point $i$ to all reachable hospitals, $\alpha_{j}$ is the class coefficient of the $j$-th hospital's scale, $S_{j}$ represents the service ability, $V_{j}$ is the competition affecting population points around the $j$-th hospital and the limited medical resources, $C_{i}$ is the population quantity of the $i$-th population point, $D_{i j}$ is the time cost based on the actual transport network between the $i$-th population point and the $j$-th hospital, $\beta$ is the impedance coefficient of distance, and $n$ and $m$ are the amounts of hospitals and population points, respectively.

The improved gravity model also considers the impact of population density on the healthcare accessibility indicator, which accounts for the influence of different-scale hospitals on the resident selection behavior. $S_{j}$ represents the hospital sickbeds and the service ability of the hospital, and $C_{i}$ is the population of this population point. The combination of the actual situation in Wuhan and the synthesis of the healthcare ability of each hospital shows that patients tend to choose professional hospitals for treatment. Therefore, $\alpha_{j}$ is 4 when the $j$-th hospital is a third-class specialized hospital, followed by 3, 2 , and 1 for third-, second-, and first-class hospitals. $\beta$ is the impedance indicator of distance. Scholars believe that $\beta$ has different mathematical expressions (e.g., linear and exponential). The scale of $\beta$ varies with the types of service and population group [13]. Considering other research methods on spatial accessibility [23], $\beta$ was widely used when $\beta=2$ in this paper. The costs of the shortest commute between the population point and the hospital were selected as healthcare costs $\left(D_{i j}\right)$.

\subsubsection{Realization of Improved Accessibility Analysis Model}

The shortest time between each population point to the nearest hospital was determined as $0.644 \mathrm{~h}$ using the nearest facility analysis in ArcGIS. This value was set as the interrupt travel time of the OD matrix in network analysis in ArcGIS. All time costs and routes between the population points to all hospitals were then established within the interrupt value using the shortest transportation network route. The time value was used as the healthcare $\operatorname{cost}\left(D_{i j}\right)$ in the improved accessibility analysis model. The accessibility between the population point to the hospital is impossible when the routes exceed the interrupt travel time.

Equations (2) and (3) calculate the healthcare accessibility indicator of each population point, which is the convenience degree of resident medical treatment $\left(A_{i}\right)$. The data are shown in Table 2.

Table 2. Healthcare accessibility indicator of each population point.

\begin{tabular}{cc}
\cline { 2 - 2 } Population Point Name & $A_{i}$ \\
\cline { 2 - 3 } Minzu Street & 304.558 \\
Minquan Street & 424.503 \\
$\ldots$ & $\ldots$ \\
Anshan Street & 4.256 \\
Liujiaoting & 1964.135 \\
Wangjiadun Airport & 298.273 \\
Jianghan Economic Development Zone & 111.175 \\
\cline { 2 - 2 }$A_{i}$ is the indicator of healthcare accessibility that represents population point $i$ to all reachable hospitals.
\end{tabular}

The data in Table 2 is hierarchically displayed on the map in Figure 2 using the Inverse Distance Weighted (IDW). This method assumes that the variable being mapped decreases in influence with distance from its measured location, which is to predict a value for any unmeasured location. Then the unknown accessibility power of anywhere will be estimated and displayed by IDW using the measured location values. Darker colors denote better healthcare accessibility. Figure 3 shows that most hospitals located in the central urban areas have better accessibility. Furthermore, places that are farther from the hospitals, which have a small accessibility indicator, are mainly in the suburbs (e.g., Anshan Street, Shu'an Town, and Mulan Street). On the whole, the accessibility was decreasing from the central urban areas to the suburbs. The places close to many hospitals have better accessibility, and they are mainly concentrated in the central city zone along the river, such as Liujiaoting and Huanghelou Street. 
The central urban area residents are provided with more medical resources, better resource quality, and shorter travel time than suburban residents.

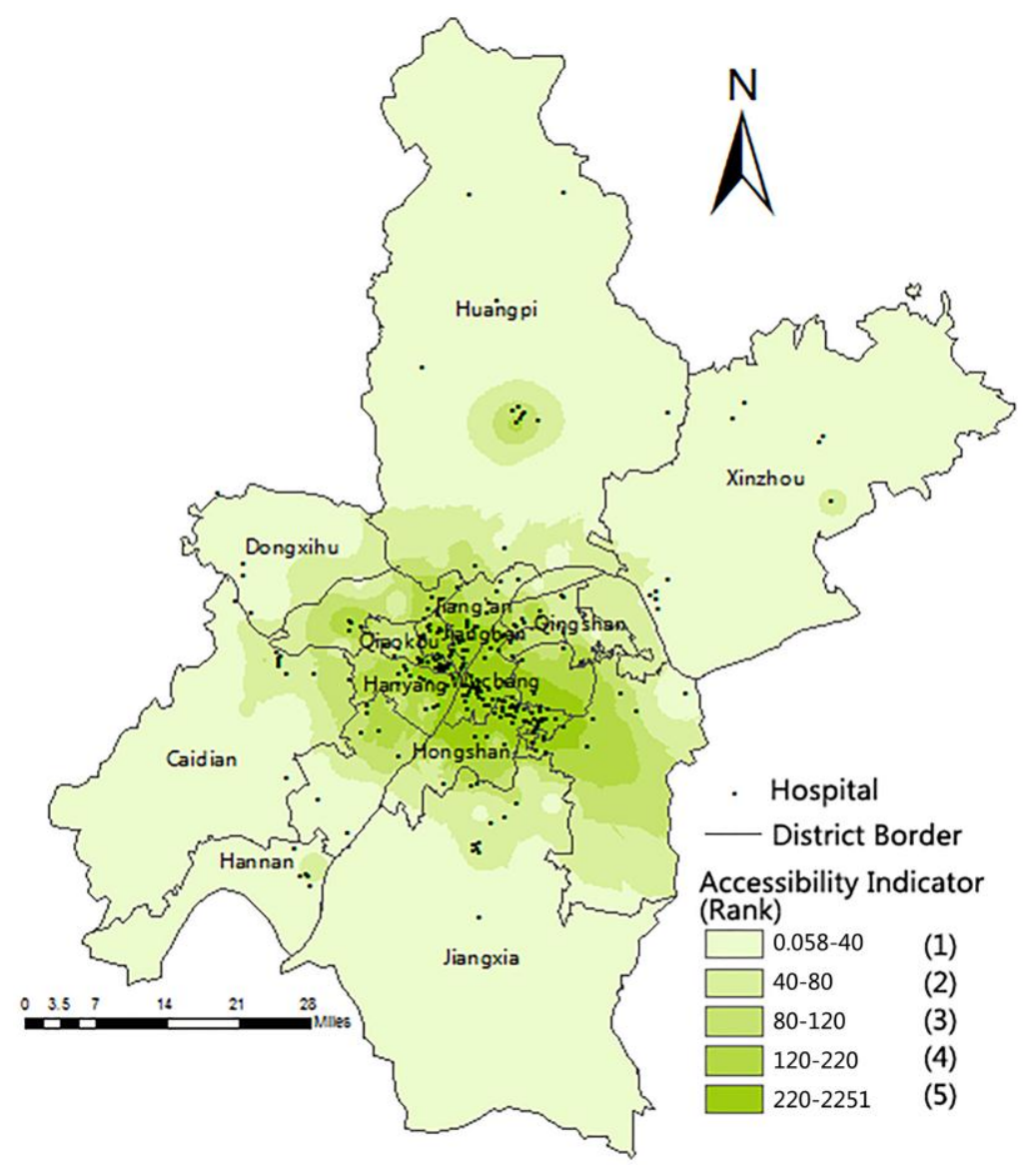

Figure 3. Medical accessibility of population points in Wuhan.

\subsubsection{Different Accessibility Analysis}

The reasons for the good accessibility of population points are as follows:

1. As the Equations (2) and (3) show, the population is negative for accessibility; thus, less population causes less negative effects.

2. One population point can reach multiple hospitals within the travel time limit.

3. Population points reach large-scale and high-class hospitals.

For instance, the Huanghelou Street is located in the central area of the Wuchang District from which 40 hospitals can be reached within the travel time limit. These hospitals offer good service, and they can be reached fast, thereby showing good accessibility. The reasons for poor accessibility are as follows:

1. The travel to hospitals takes long.

2. Few hospitals can be reached.

Shu'an Town is located in the south of the Jiangxia District at the border of Wuhan. The town is inaccessible and remote, with poor healthcare accessibility. 


\subsection{Treatment Analysis}

\subsubsection{Improved Huff Model}

Gravity modeling techniques significantly contribute to solving these retail network management issues [24]. The Huff model assumes that the consumption rate in a commercial facility is proportional to the effectiveness of the selection $[25,26]$. This solves the service area division problem for multiple stores and calculates the probability of selecting a commercial zone among consumers [27].

The Huff model can be appropriately used for the simulation of treatment situations of a population point and the frequency calculation of people seeing doctors in a hospital. The combination along with the research on the spatial distribution of medical facilities in Wuhan improves the Huff model.

$$
\begin{gathered}
P_{i j}=A_{i j} / \sum_{j=1}^{n} A_{i j} \\
E_{j}=\sum_{i=1}^{n}\left(P_{i j} C_{i} k\right) \\
k=X / 365 Y \\
H_{j}=E_{j} / G_{j}
\end{gathered}
$$

$A_{i j}$ in Equation (4) is the gravitational force between the $j$-th hospital and the $i$-th population point, which relies on Equation (2). $P_{i j}$ is the medical probability between the $i$-th population point and the $j$-th hospital. In Equation (5), $E_{j}$ is the daily potential outpatient population; $C_{i}$ is the population of the $i$-th population point; and $k$ is the coefficient of the daily average of outpatient population. In Equation (6), $X$ is the number of outpatients in a whole year, and $Y$ is Wuhan's population in that year. In Equation (7), $H_{j}$ is the ratio of $E_{j}$ and $G_{j}$, where $G_{j}$ is the number of actual daily outpatients of the $j$-th hospital. The use of resources of the $j$-th hospital is reflected in the map by the $H_{j}$ value. If the ratio $H_{j}$ is less than 1 , the actual demand of hospital resources is higher than the hospital supply. Therefore, this area lacks medical resources. Conversely, if the ratio is bigger than 1 , the medical resources are redundant in that area.

\subsubsection{Realization of Improved Huff Model}

The Wuhan Health Yearbook (2013) [28] shows that the total clinical patient service in 2012 in Wuhan equals 33,157,647 person-time, and the total population in Wuhan at the end of 2012 was $8,717,524$. The coefficient $k$ is 0.010421 based on the Equation (5). The daily potential outpatient populations of each hospital $\left(E_{j}\right)$ —calculated using Equations (3), (4) and (6)—are shown in Table 3.

Table 3. Daily potential outpatient population of each hospital in Wuhan.

\begin{tabular}{cc}
\hline Hospital Name & $\begin{array}{c}\text { Daily Potential Outpatient Population } E_{j} \\
\text { (Person-Time/Hospital) }\end{array}$ \\
\hline The Hospital of South-central University for Nationalities & 15 \\
Dongshan Hospital & 22 \\
Hubei General Hospital & 2572 \\
$\ldots$ & $\ldots$ \\
Jiangxia Traditional Chinese Medicine Hospital & 64 \\
Chinese People's Liberation Army 161st Central Hospital & 1134 \\
\hline
\end{tabular}

Based on the year-round outpatients from National Most Hospital Directory and Outpatient report, the daily average of outpatients and their weighting in Wuhan hospitals were calculated and displayed in Table 4. This paper mainly studies general, Chinese traditional medicine, and specialized hospitals, which represent the most common types of hospitals that residents usually 
choose. The Wuhan Health Yearbook (2013) [28] indicated that the total outpatients $\left(Z_{r}\right)$ in 2012 for the general, Chinese traditional medicine, and specialized hospitals (including maternal and child health hospitals) were 23,633,095; 2,985,144; and 4,252,292, respectively. According to the Equation (8), the actual daily average of outpatients (Table 5) for different classes and hospital types was calculated by weighting the values in Table 4 .

$$
O_{r h}=Z_{r} W_{h} / 365 Q_{r h}
$$

in Equation (8), $r$ represents general, Chinese traditional medicine, and specialized hospitals; $h$ represent third-, second-, first-class hospital; $O_{r h}$ is the actual daily average of outpatients; $Z_{r}$ is total outpatients about the $r$-th hospital, $W_{h}$ is the weighting of $h$-th hospital; $Q_{r h}$ is the sum of " $r h^{\text {" hospitals }}$ in Wuhan. For example, if $r$ is for Chinese traditional medicine hospital and $h$ is for third-class hospital, $Q_{r h}$ means the quantity of Chinese traditional medicine third-class hospitals.

Table 4. Daily outpatient population and weighting in Wuhan.

\begin{tabular}{ccccc}
\hline Hospital Class & $\begin{array}{c}\text { Third-Class } \\
\text { Hospital }\end{array}$ & $\begin{array}{c}\text { Second-Class } \\
\text { Hospital }\end{array}$ & $\begin{array}{c}\text { First-Class } \\
\text { Hospital }\end{array}$ & Sum \\
\hline Daily Average Outpatients (Person-Time) & 2300 & 250 & 150 & 2700 \\
Weighting of Outpatient $\left(\boldsymbol{W}_{\boldsymbol{h}}\right)$ & 0.85 & 0.09 & 0.06 & 1 \\
\hline
\end{tabular}

Table 5. Daily actual average of outpatients in Wuhan.

\begin{tabular}{ccc}
\hline Hospital Class & Hospital Type & $\begin{array}{c}\text { Daily Actual Average Outpatients } \boldsymbol{O}_{\boldsymbol{r h}} \\
\text { (Person-Time/Hospital) }\end{array}$ \\
\hline \multirow{3}{*}{ Third-Class Hospital } & General Hospital & 2201 \\
\cline { 2 - 3 } & Chinese Traditional Medicine Hospital & 2317 \\
\cline { 2 - 3 } Second-Class Hospital & Specialized Hospital & 1142 \\
\cline { 2 - 3 } & General Hospital & 243 \\
\cline { 2 - 3 } & Chinese Traditional Medicine Hospital \\
\hline \multirow{3}{*}{ First-Class Hospital } & Specialized Hospital & 245 \\
\cline { 2 - 3 } & General Hospital & 736 \\
\cline { 2 - 3 } & Chinese Traditional Medicine Hospital & 27 \\
\cline { 2 - 3 } & Specialized Hospital & 29 \\
\hline
\end{tabular}

The clinic ratio model was established using the daily potential outpatient quantity of each hospital from Table 3 and the daily actual average outpatients of each different class and different hospital type from Table 5 (see Equation (6) and Table 6).

Table 6. Ratio of potential daily outpatients and actual daily average of outpatients for each hospital in Wuhan (Portion).

\begin{tabular}{cc}
\hline Hospital Name & Ratio \\
\hline Hospital of the South-Central University For Nationalities & 0.56587 \\
Dongshan Hospital & 0.820014 \\
Hubei General Hospital & 1.168633 \\
$\ldots$ & $\ldots$ \\
$\ldots$ & 2.361732 \\
Jiangxia Traditional Chinese Medicine Hospital & 0.51528 \\
\hline
\end{tabular}

Figure 4 shows that the data in Table 6 is reflected by the IDW in ArcGIS. The light-colored region represents the area with medical resource shortage, and the deep-colored region indicates areas with redundant resources. As a consequence from Figure 4, the most central urban areas are in shortage of 
medical resources, medical resources are adequate in the suburbs reversely, especially in the central district of suburbs.

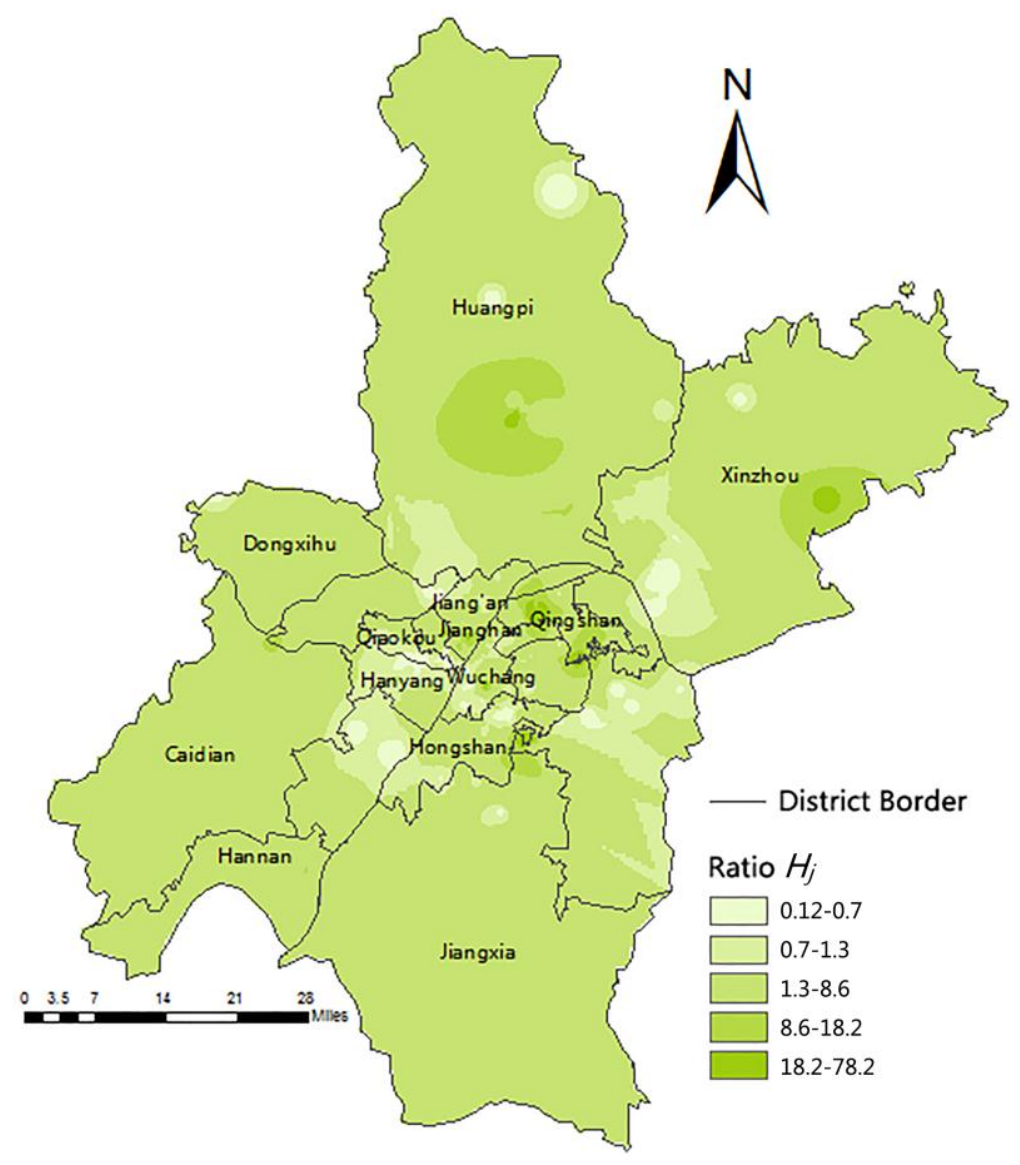

Figure 4. Ratio of potential daily outpatients and actual daily average of outpatients of each hospital in Wuhan in hypsometric layers.

\subsubsection{Difference Analysis of Outpatient Quantity}

The actual number of outpatients was higher than the number of outpatients that existing medical resources can serve when the hospital ratio $H_{j}$ was less than 0.7. The light-colored area in Figure 3 has few medical resources, but on the other hand, some of them have high population densities, such as the northern part of the Hanyang District and the joint area between the Wuchang and Hongshan Districts, even though these areas have high-class, large-scale hospitals. However, the resources are limited. Hubei Maternal and Child Health Hospital in the Hongshan District serve beyond 100,000 people within $2 \mathrm{~km}$. Moreover, residents from other distant places choose high-class hospitals around the central urban area for good medical service, which lead to resource shortage, because the actual outpatient quantity is higher than the outpatient capacity. Areas, such as the eastern part of the Hongshan District and the northern part of the Hannan District, have an adequate amount of medical resources when the ratio ranges between 0.7 and 1.3. The deep colored area with a ratio between 1.3 and 18.2 represents areas with minimal redundant resources.

The resources of the suburbs are reasonable because the suburbs have few hospitals and few residents. A ratio $\left(H_{j}\right)$ above 1 reflects minimal redundancy for these large areas. Moreover, when the ratio is higher than 18.2, the medical resources in the area are redundant, such as in the center of the Huangpi and Xinzhou Districts. Combined with Section 3.1, despite there being better accessibility in central urban areas, there is a medical resources shortage here; meanwhile, there is adequate medical resources for few people with bad accessibility in suburbs. 
Therefore, some effective measures should be taken to improve this phenomenon. The new hospital location should be selected according to different spatial accessibilities to solve medical resource shortage problems.

\subsection{Hospital Location Selection Based on the Multi-Criteria Evaluation Analysis}

The multi-criteria evaluation (MCE) analysis provides a solution for program assessment that includes multiple factors, multiple standards, and conflicting factors [14]. Combined with the geographic information system, thematic maps can be generated to indicate risk degrees [29]. New hospital locations were found by MCE in regions with resource shortages and bad accessibility.

\subsubsection{MCE Model}

Based on a review in the Urban Public Facilities Planning Specification (GB50442-2008) and research on the maximum usage of limited data, the criteria for hospital location selection and the layout in Wuhan are as follows (Table 7). The larger the weight is, the more important the criterion is.

1. Transportation around the location is convenient.

2. The hospital is close to a densely populated area.

3. The new location is far from existing hospitals.

4. The area and scale of the new hospital should be appropriate.

Table 7. Criteria and normalized weight allocation of location selection.

\begin{tabular}{cc}
\hline Criteria & Normalized Weight \\
\hline Area of Bad Accessibility A & 0.3 \\
Close to the Population Point B & 0.3 \\
Far from the Existing Hospital C & 0.1 \\
Lack of Resources Area D & 0.3 \\
The Scale of the Hospital Matches the Population & Later to Judge \\
\hline
\end{tabular}

The hierarchical data for rule A were reclassified according to the legend in Figure 3, and the results are presented in the brackets named Ranks from 1 to 5 . The smaller the rank number is, the lower the accessibility is, which means that more new hospitals are necessary.

The medical resource competition between different population points in rule B is reflected by reclassifying the population points according to the population quantity and the weighting of results (Table 8). The population suitable map was obtained using the Euclidean distance. The Euclidean distance output raster contains the measured distance from every cell to the nearest source. After this analysis, the map was reclassified afterwards. Ranks 1 to 5 represent the subsections of $0-2,2-4$, $4-6,6-8$, and $>8 \mathrm{~km}$. The final result $P G$ means the density of people, which was calculated using the weight in Table 8 and Equation (9), as shown in Figure 5a. A lower value indicates a larger population density in the area.

Table 8. Population-normalized weight allocation.

\begin{tabular}{cc}
\hline Type of Population & Weight \\
\hline >40,000: a & 0.3 \\
30,000-40,000: b & 0.2 \\
20,000-30,000: c & 0.2 \\
10,000-20,000: d & 0.2 \\
$0-10,000: \mathrm{e}$ & 0.1 \\
\hline
\end{tabular}

After reclassifying the population data, the dataset was calculated by Equation (9).

$$
P G=a \times 0.3+b \times 0.2+c \times 0.2+d \times 0.2+e \times 0.1
$$


for rule $\mathrm{C}$, the hospitals were analyzed using the Euclidean distance, and the raster results were reclassified. The reclassification standards were the same as those used for rule B. The results are shown in Figure 5b. A lower value indicates smaller hospitals in this area.

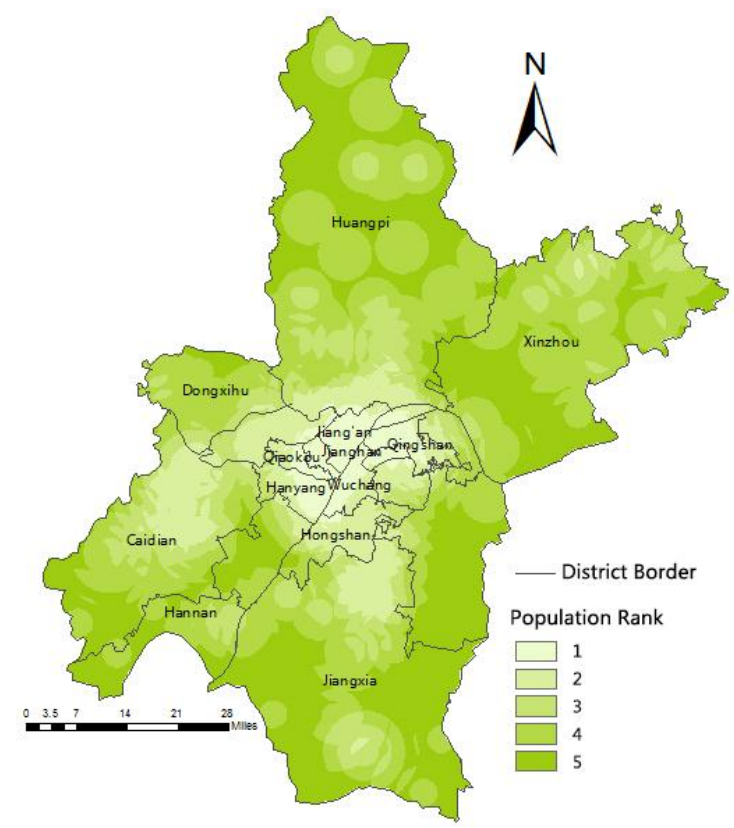

(a)

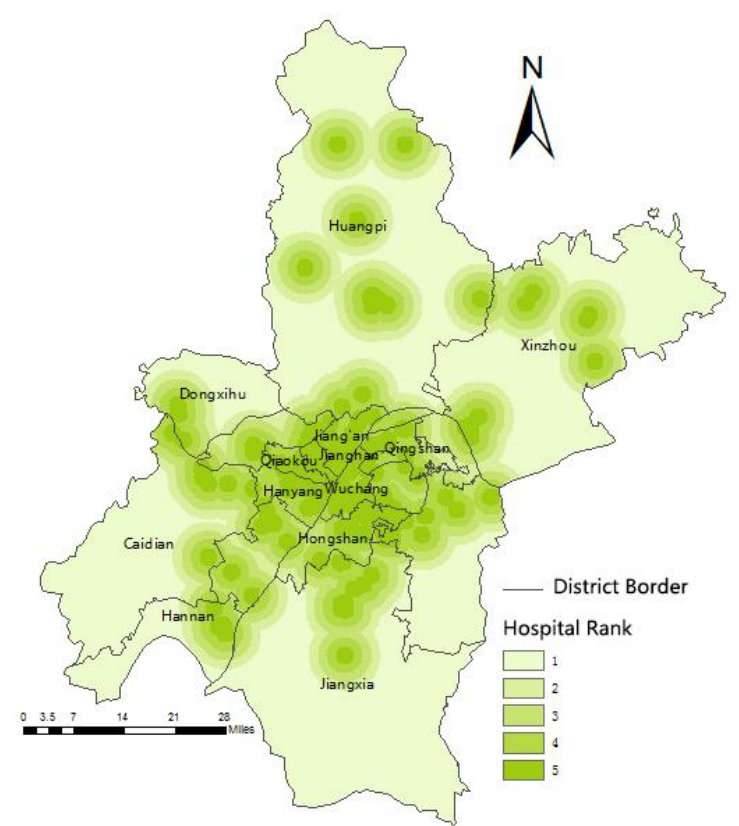

(b)

Figure 5. Suitable map after reclassification. (a) These regions refer to the population points. The lower the value is, thegreater the population intensity is. (b) These regions are about existing hospitals. The lower the value is, the more a new hospital is necessary.

For rule $\mathrm{D}$, the reclassification and ranking of the legend were performed according to the same standards in Figure 4.

\subsubsection{MCE Model Realization}

According to the criteria and weights, the equation for the hospital location selection can be expressed as following in Equation (10):

$$
\text { SUM }=A \times 0.3+B \times 0.3+C \times 0.1+D \times 0.3
$$

the Equation (10) findings and the ArcGIS Raster Calculator (Figure 6) calculation results were overlaid with the land use classification raster map (Figure 7) resulting in Figure 8. A lower value reflects a higher urgency for medical resources or hospitals. The red colored area represents these urgent areas, whereas the green colored areas denote those with appropriate resources. 


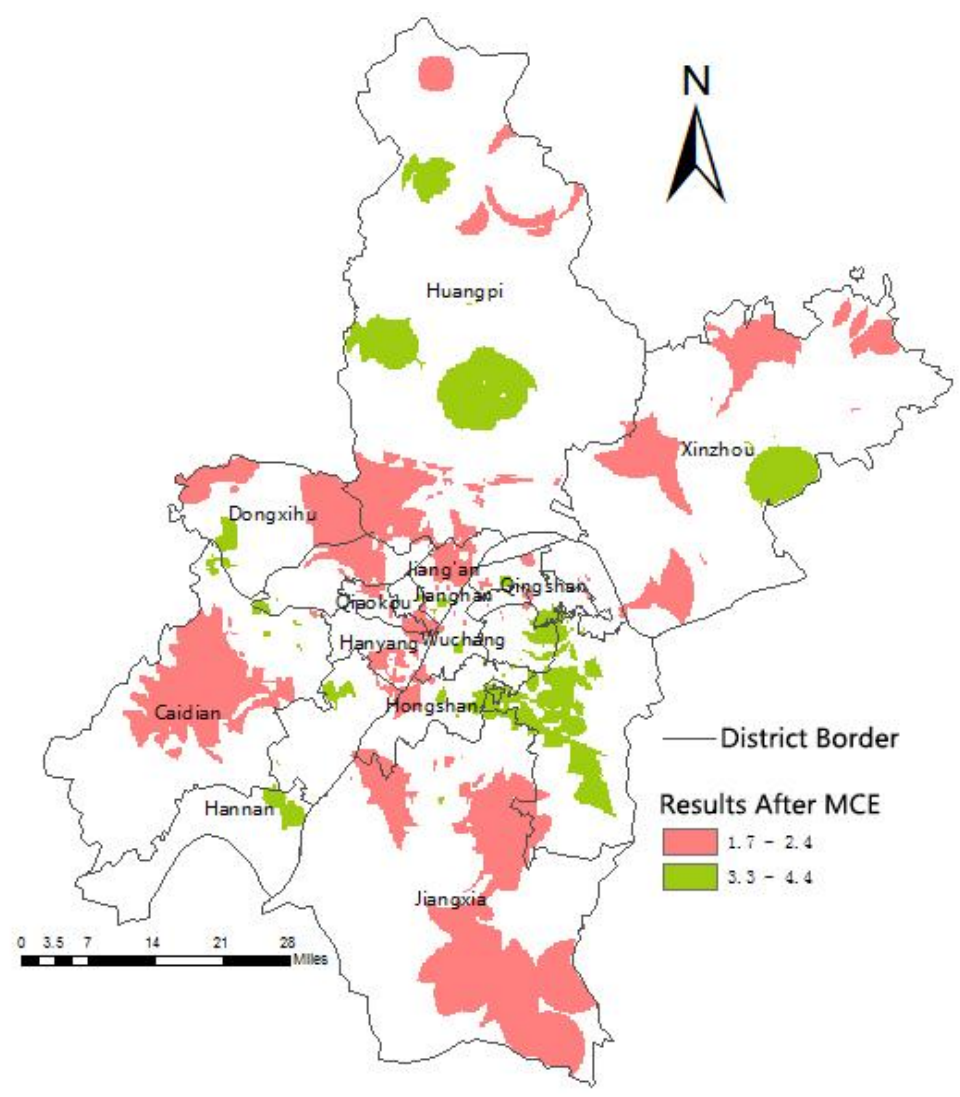

Figure 6. Unremoved non-building land location selection results. MCE = multi-criteria evaluation.

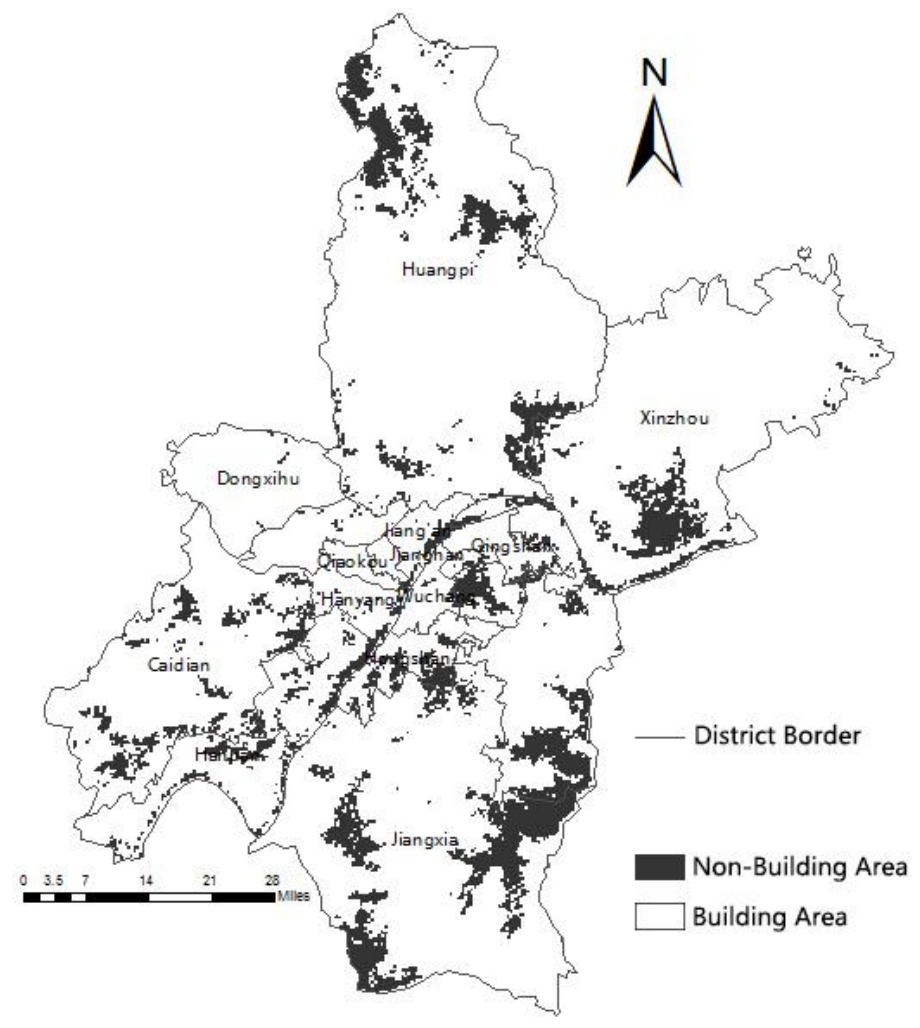

Figure 7. Land use classification map. 


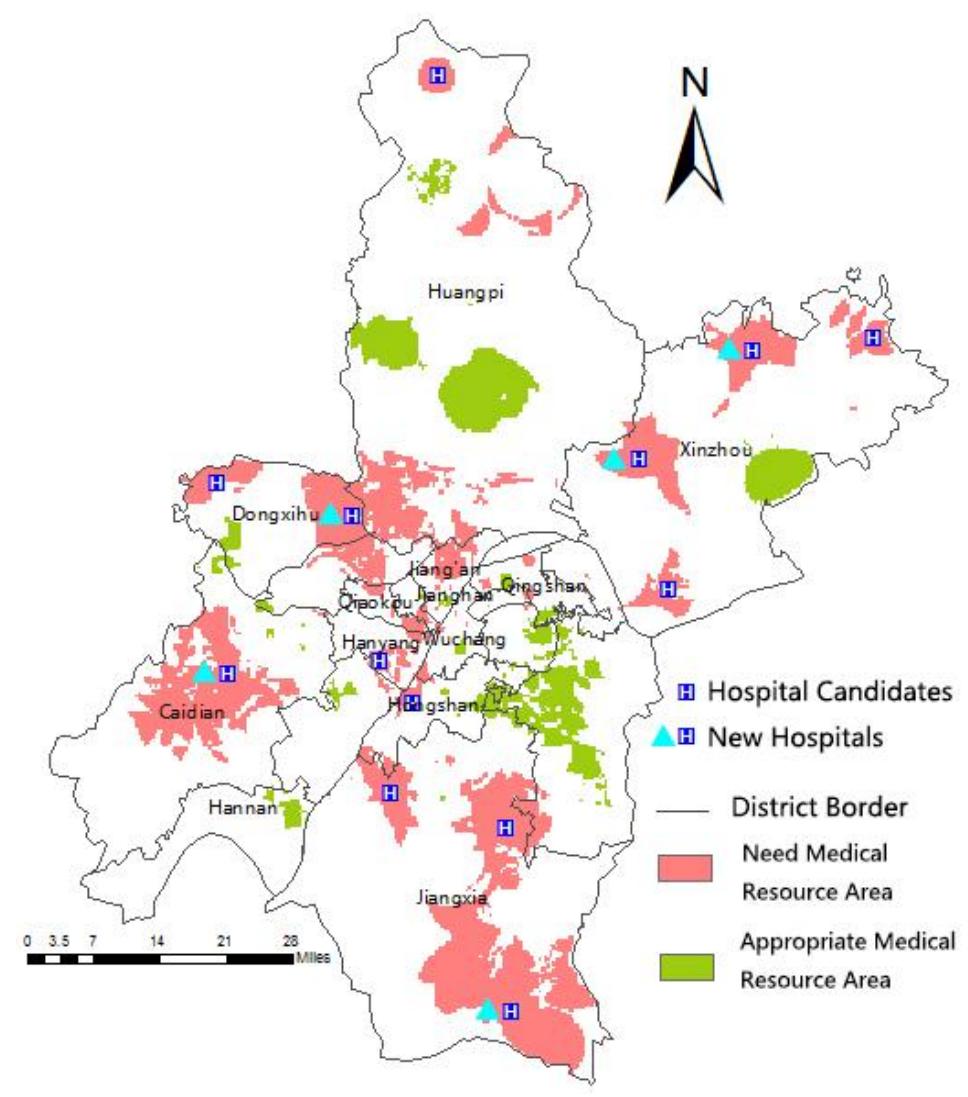

Figure 8. Removal of the non-building land location selection results.

\subsubsection{MCE Model Assessment}

The red region in the central urban area shows insufficient per capita healthcare resources because of the large population density, even though the accessibility is good. Thus, the existing hospitals should be expanded or the doctor number should be increased in the red regions to ease the pressure of a large population density and to ameliorate the availability of medical resources. On the other hand, the red regions in the suburbs are areas without hospitals and with bad accessibility; whereas several population points need healthcare here and these suburban areas have sufficient medical resources. Thus, transforming existing hospitals into higher-class hospitals and building additional first-class hospitals or health centers in remote areas would be beneficial.

The centers in the red region were regarded as candidates for new suburban hospital locations for verifying the feasibility of the location selection method (Figure 8). The new hospital location was used as the facility point, whereas the population point was used as the requesting point in the location-allocation model in ArcGIS. Several locations which needed minimum facilities for service and covered a maximum part of the land were selected. A large number of experiments supposed that first-class hospitals should be constructed in the suburbs with an average of 30 sickbeds. Thus, the medical accessibility for residents in the suburbs can be improved by building only seven hospitals.

No notable effects on the central urban area were observed after new hospital locations were selected. However, accessibility in the suburbs was affected (Table 9). Only the Hangyang District showed increased medical accessibility among the seven central districts. The Xinzhou District displayed a larger rate of suburban area increase, whereas the Dongxihu District indicated a rate lower than those of the other districts. The overall medical accessibility indicators increased by $0.163 \%$. The accessibility in the central urban and suburban areas increased by $0.085 \%$ and $2.682 \%$, respectively. 
Table 9. Changes after the addition of new hospitals.

\begin{tabular}{|c|c|c|c|c|c|c|}
\hline District & Property & $\begin{array}{c}\text { Number of } \\
\text { New } \\
\text { Hospitals }\end{array}$ & $\begin{array}{c}\text { Average of } \\
\text { Accessibility } \\
\text { Indicator for } \\
\text { Population Point } \\
\text { before Adding } \\
\text { Hospital }\end{array}$ & $\begin{array}{l}\text { Average of } \\
\text { Accessibility } \\
\text { Indicator for } \\
\text { Population Point } \\
\text { after Adding } \\
\text { Hospitals }\end{array}$ & Increase (\%) & $\begin{array}{c}\text { Central/ } \\
\text { Suburb } \\
\text { Area } \\
\text { Increase (\%) }\end{array}$ \\
\hline Jianghan & Central & 0 & 400.331 & 400.483 & 0.038 & \multirow{7}{*}{0.085} \\
\hline Qiaokou & Central & 0 & 516.093 & 516.297 & 0.04 & \\
\hline Jiang'an & Central & 0 & 328.065 & 328.197 & 0.04 & \\
\hline Wuchang & Central & 0 & 580.231 & 580.306 & 0.013 & \\
\hline Qingshan & Central & 0 & 102.124 & 102.165 & 0.039 & \\
\hline Hangyang & Central & 1 & 172.565 & 173.372 & 0.468 & \\
\hline Hongshan & Central & 0 & 186.402 & 186.324 & -0.042 & \\
\hline Hannan & Suburb & 0 & 14.907 & 15.003 & 0.646 & \multirow{6}{*}{2.682} \\
\hline Dongxihu & Suburb & 1 & 61.443 & 61.714 & 0.442 & \\
\hline Caidian & Suburb & 1 & 18.543 & 19.397 & 4.604 & \\
\hline Xinzhou & Suburb & 2 & 9.159 & 9.602 & 4.842 & \\
\hline Huangpi & Suburb & 1 & 18.973 & 19.383 & 2.16 & \\
\hline Jiangxia & Suburb & 1 & 15.494 & 16.021 & 3.402 & \\
\hline Sum & - & 7 & 191.732 & 192.045 & 0.163 & - \\
\hline
\end{tabular}

\section{Conclusions}

This research demonstrated the following:

1. The majority-71.5\% - of the hospitals are in the central urban area in Wuhan. The hospital density of Wuhan reached 0.23 places $/ \mathrm{km}^{2}$, whereas, it was less than 0.01 places $/ \mathrm{km}^{2}$ in the suburbs.

2. The medical accessibility in the central urban area is better than in the suburbs. Regions with good accessibility are located in the central area. Accessibility decreases from the central area to the suburbs.

3. Although there is better healthcare accessibility, medical resources are short for people in the central urban area. The suburbs have bad healthcare accessibility but there is sufficent medical resources.

Combined with land use classification information and MCE analysis, healthcare accessibility was improved. Seven new hospital locations were chosen by the ArcGIS location allocation model to ameliorate accessibility in the suburbs.

With the methods of the improved gravity model and Huff model, the distribution characteristics of hospital in Wuhan could be understood, as well the regional accessibility and usage of medical resources as well. Then we put forward some solutions to improve the medical services for these factors. While more factors should be considered in this research. More types of hospitals should be considered for this research, such as community clinics. The location selection of some specialized hospitals that only for women or men or some age grades should be considered with sex or age standardized, rather than the whole population. Large-scale population data were used for this research because of the lack of population data on housing estates. Whether urban residents at the city border would select hospitals in the Wuhan city remains unclear. The relevant factors that influenced the research results of this paper should be further refined in a future study.

Acknowledgments: This research was financially supported by the National Natural Science Foundation of China (41201474, 41401449).

Author Contributions: Nai Yang and Shiyi Chen conceived and designed the experiments; Shiyi Chen and Weilu Hu performed the experiments; Zhongheng Wu and Yi Chao analyzed the data; Nai Yang and Shiyi Chen wrote the paper. 
Conflicts of Interest: The authors declare no conflict of interest. The founding sponsors had no role in the design of the study; in the collection, analyses, or interpretation of data; in the writing of the manuscript, and in the decision to publish the results.

\section{References}

1. World Health Organization. Increasing Access to Health Workers in Remote and Rural Areas through Improved Retention: Global Policy Recommendations. Available online: http://www.who.int/hrh/ retention/guidelines/en/ (accessed on 11 August 2016).

2. Goodman, D.C.; Fisher, E.; Stukel, T.A.; Chang, C.H. The distance to community medical care and the likelihood of hospitalization: Is close always better? Am. J. Public Health 1997, 87, 1144-1150. [CrossRef] [PubMed]

3. Jia, P.; Xierali, I.M.; Wang, F. Evaluating and re-demarcating the hospital service areas in Florida. Appl. Geogr. 2015, 60, 248-253. [CrossRef]

4. Gao, J.B.; Zhou, C.S.; Jiang, H.Y.; Ye, C.D. The research on the spatial differentiation of the urban public service facilities distribution in Guangzhou. Hum. Geogr. 2010, 3, 78-83.

5. Lu, X.X. The Evaluation Research of the Compulsory Education Development Balance Based on the Spatial Version. Ph.D. Thesis, Nanjing Normal University, Nanjing, China, 1 June 2011.

6. Cao, J.H.; Chen, J.G.; Huo, J.T.; Wu, F. Research on the health equity theory and methodology. Northwest Med. Educ. 2006, 6, 788-792.

7. Gao, J.B.; Fu, J.B.; Ye, C.D. Spatial characteristics and causes of urban public service facilities in Guangzhou City. Areal Res. Dev. 2012, 6, 70-75.

8. McGrail, M.R.; Humphreys, J.S. Measuring spatial accessibility to primary health care services: Utilising dynamic catchment sizes. Appl. Geogr. 2014, 54, 182-188. [CrossRef]

9. McGrail, M.R.; Humphreys, J.S. Measuring spatial accessibility to primary care in rural areas: Improving the effectiveness of the two-step floating catchment area method. Appl. Geogr. 2009, 29, 533-541. [CrossRef]

10. Ngamini Ngui, A.; Vanasse, A. Assessing spatial accessibility to mental health facilities in an urban environment. Spat. Spat. Epidemiol. 2012, 3, 195-203. [CrossRef] [PubMed]

11. Ford, A.; Barr, S.; Dawson, R.; James, P. Transport accessibility analysis using GIS: Assessing sustainable transport in London. ISPRS Int. J. Geoinf. 2015, 4, 124-149. [CrossRef]

12. Guagliardo, M.F. Spatial accessibility of primary care: Concepts, methods and challenges. Int. J. Health Geogr. 2004, 3, 3. [CrossRef] [PubMed]

13. Song, Z.L.; Chen, W.; Che, Q.J.; Zhang, L. Measurement of spatial accessibility to health care facilities and defining health professional shortage areas based on improved potential model. Sci. Geogr. Sin. 2010, 2, 213-219.

14. Tang, S.J. The Research of Spatial Layout and Location of Public Service Facility Based on GIS. Master's Thesis, Central South University, Changsha, China, 1 November 2008.

15. Yang, G.; Song, C.; Shu, H.; Zhang, J.; Pei, T.; Zhou, C. Assessing patient bypass behavior using taxi trip origin-Destination (OD) data. ISPRS Int. J. Geoinf. 2016, 5, 157. [CrossRef]

16. Basu, J.; Friedman, B. A re-examination of distance as a proxy for severity of illness and the implications for differences in utilization by race/ethnicity. Health Econ. 2007, 16, 687-701. [CrossRef] [PubMed]

17. Hubei Bureau of Surveying, Mapping, and Geoinformation. Available online: http://www.hbschj.com.cn/ (accessed on 11 August 2016).

18. Baidu. Baidu Map. Available online: http://www.map.baidu.com (accessed on 11 August 2016).

19. Wuhan Bureau of Statistics; Naitonal Bureau of Statistics Wuhan Investigation Team. Wuhan Statistical Yearbook (2014); China Statistics Press: Beijing, China, 2014; pp. 409-410.

20. Humphreys, J.S. Delimiting "rural": Implications of an agreed "rurality" index for healthcare planning and resource allocation. Aust. J. Rural Health 1998, 6, 212-216. [CrossRef] [PubMed]

21. Dussault, G.; Franceschini, M.C. Not enough there, too many here: Understanding geographical imbalances in the distribution of the health workforce. Hum. Resour. Health 2006, 4, 12. [CrossRef] [PubMed]

22. Hansen, W.G. How accessibility shapes land use. J. Am. Inst. Plan. 1959, 25, 73-76. [CrossRef]

23. Peeters, D.; Thomas, I. Distance predicting functions and applied location-allocation models. J. Geogr. Syst. 2000, 2, 167-184. [CrossRef]

24. Huff, D.L. Defining and Estimating a Trade Area. J. Mark. 1964, 28, 34-38. [CrossRef] 
25. Wu, Z.C. Remodified model of location of urban trade areas based on Huff modified Model. J. Jishou Univ. 2009, 2, 108-111.

26. De Beule, M.; Van den Poel, D.; van de Weghe, N. An extended Huff-model for robustly benchmarking and predicting retail network performance. Appl. Geogr. 2014, 46, 80-89. [CrossRef]

27. Li, Y.F.; Pan, H.Z.; Tian, L.; Wu, Y. Modification of Huff model and its application in urban commercial network planning: A case of Changzhou City, Jiangsu Province. Arid Land Geogr. 2014, 4, 802-811.

28. Wuhan Health Yearbook Compilation and Editing Committee. The Wuhan Health Yearbook (2013); Wuhan Press: Wuhan, China, 2013; pp. 401-402.

29. Fuller, D.O.; Williamson, R.; Jeffe, M.; James, D. Multi-criteria evaluation of safety and risks along transportation corridors on the Hopi Reservation. Appl. Geogr. 2003, 23, 177-188. [CrossRef]

(C) 2016 by the authors; licensee MDPI, Basel, Switzerland. This article is an open access article distributed under the terms and conditions of the Creative Commons Attribution (CC-BY) license (http://creativecommons.org/licenses/by/4.0/). 